\title{
Novas perspectivas de avaliação do aluno de EaD no paradigma da cibercultura e a web $\mathbf{2 . 0}$
}

\author{
Eduardo Santos Junqueira \\ Universidade Federal do Ceará
}

\section{Resumo}

0 trabalho discute contribuições oferecidas pelos paradigmas da cibercultura e da Web 2.0 às formulações sobre a avaliação da aprendizagem do aluno, em particular na modalidade da educação a distância, EaD. Parte-se de uma reflexão sobre os avanços e limites da avaliação em EaD para a proposição de sua expansão a fim de abarcar ações do aluno relacionadas ao processo de navegação e aprendizagem no ciberespaço. Argumenta-se que tais ações extrapolam os limites do ambiente virtual de aprendizagem e estão relacionadas às novas práticas de interação, colaboração, coautoria e apropriação criativa vivenciadas por muitos alunos. Novas formas de avaliação permitem atribuir valor a essas ações e elevar a qualidade dos processos de aprendizagem.

Palavras-chave: Avaliação. Educação a distância. Web 2.0. Cibercultura. 


\section{New perspectives on online student evaluation in the paradigm of cyberspace and the web $\mathbf{2 . 0}$}

This paper centers on the contributions offered by the paradigm of cyberculture and the Web 2.0 to propositions relating to the evaluation of student learning, in particular online learning. The paper targets the advances and limitations of current practices in online education, then proposing their expansion to encompass students' browsing and their learning process in cyberspace. It is argued that such activities reach beyond the limits of the virtual learning environment and are related to the new practices of interaction, collaboration, co-authoring and creative appropriation experienced by many students. New forms of evaluation allow for assigning value to these activities and raising the quality of learning processes.

Keywords: Evaluation. Online learning. Web 2.0. Cyberculture.

\section{Nuevas perspectivas sobre la evaluación de los estudiantes en línea en el paradigma del ciberespacio y la web 2.0}

El trabajo se centra en las contribuciones ofrecidas por el paradigma de la cibercultura y la Web 2.0 a las propuestas sobre la evaluación del aprendizaje de los estudiantes, y en particular, el aprendizaje en línea. Se parte del papel de los objetivos de los avances y limitaciones de las prácticas actuales en la educación en línea para proponer su expansión para abarcar la navegación de los estudiantes y su proceso de aprendizaje en el ciberespacio. Se argumenta que estas acciones van más allá de los límites del entorno de aprendizaje virtual de la institución. La interacción, colaboración, cocreación y apropiación creativa se han convertido en cada vez más promulgadas por muchos estudiantes, pidiendo nuevas formas de evaluación que permiten a los maestros para asignar valor a estas acciones y mejorar la calidad del aprendizaje.

Palabras clave: La evaluación. El aprendizaje en línea. Web 2.0. Cibercultura. 


\section{Introdução}

No campo da educação a distância (EaD) no Brasil, o advento da cibercultura e a natureza midiática e comunicacional da Web 2.0 têm-se traduzido em maior ou menor ênfase, a depender do projeto pedagógico e do perfil da instituição de ensino, no uso das diversas ferramentas de um ambiente virtual de aprendizagem (AVA). Tais usos são destinados à realização de atividades programadas mais ou menos centrais no desenvolvimento das disciplina (fóruns, chats, troca de mensagens) e ao acesso a conteúdos (tutoriais, videoaulas, arquivos de texto, eslaides, infográficos e animações). Os AVA das diversas instituições constituem significativos avanços da EaD atual, porém os processos pedagógicos, a estrutura e as ferramentas dos AVA parecem não mais abarcar porções significativas das ações empreendidas pelos alunos dessa modalidade na internet, no contexto formal do ensino e da aprendizagem, e que se constituem associadas às práticas da cibercultura e "capabilidades" da Web 2.0. Essas ocorrências têm implicações para os diversos aspectos dos cursos na modalidade EaD (conteúdos, metodologias, ação tutorial e avaliação da aprendizagem), como exemplifico a seguir.

Ao atuar como professor e tutor em disciplinas na modalidade da EaD, tenho sido surpreendido pela autonomia dos meus alunos ao desenvolverem diversas atividades de estudo utilizando-se dos recursos da internet. Muitos realizam pesquisas buscando aprofundar conteúdos e relatam o acesso a web sites diversos, alguns ainda desconhecidos para mim. Eles também participam de fóruns e comunidades virtuais, escrevem comentários sobre vídeos, publicam apresentações de eslaides, realizadas para a disciplina, em web sites de compartilhamento, alguns muito populares na internet. Outros alunos me enviam os endereços dos blogs que criaram para a disciplina, onde publicam conteúdos textuais, vídeos e web links para outros web sites relacionados aos conteúdos curriculares. Colegas que atuam na área relatam experiências semelhantes.

No entanto, raramente essas ações dos alunos são contempladas pelas práticas de avaliação da aprendizagem correntes em EaD, em geral focadas nas ações do aluno restritas ao AVA. Isso constitui um problema a ser examinado. Esse artigo apresenta reflexões sobre a compreensão e formulação de perspectivas e práticas de avaliação do aluno participante dessa modalidade de ensino de forma articulada à proposta de fomento da autonomia e do engajamento do aluno em ações colaborativas baseadas no uso das tecnologias de comunicação e informação (TICs) em rede, na internet. 


\section{Problemática}

0 cerne do problema refere-se ao fato de que, assim como o conhecimento encontra-se cada vez menos circunscrito aos muros das instituições educacionais, no caso da EaD este está cada vez menos delimitado pelas fronteiras do ambiente virtual de aprendizagem (AVA). As ações do aluno no AVA e no ciberespaço constituem-se em estreita relação com processos de cognição distribuída, relacionados à "representação do conhecimento tanto dentro da cabeça dos indivíduos [internalizada, de caráter cerebral] como no mundo [...] o conhecimento se propaga entre diferentes indivíduos e artefatos" (Nardi, 1995, p. 38, tradução nossa). Tal perspectiva institui, portanto, a unidade de análise do sistema cognitivo distribuído, que é composto pelos indivíduos, suas ações de estudo e os artefatos (concretos e virtuais) que utilizam. Outro elemento fundamental da cognição distribuída está na “compreensão da coordenação entre indivíduos e artefatos, ou seja, a compreensão sobre como agentes individuais se alinham e compartilham um processo distribuído" (Nardi, 1995, p. 39, tradução nossa).

Nessa perspectiva da cognição distribuída, a dimensão material engloba todos os artefatos mentais e físicos nos quais a cognição encontra-se encapsulada, enquanto a dimensão social refere-se aos outros participantes que, de alguma forma, contribuem nessa atividade cognitiva, atuando como fontes de cognição. Os artefatos materiais (livros) e virtuais (AVAs, web sites, vídeos) contribuem com a cognição distribuída porque podem guiar, aglutinar e estruturar a atividade. Possibilitam, ainda, armazenar o trabalho intelectual e ajudar a evitar erros, como ocorre com a utilização de sistemas de inteligência artificial e de suporte mútuo entre usuários via fórum, entre outros (Pea, 1993).

A despeito do avanço e consolidação desses fenômenos, prevalecem, no caso da EaD, formas de avaliação associadas ao ensino presencial e circunscritas às atividades do aluno no AVA, focadas nas frequências de acessos e nos conteúdos escritos disponibilizados pelo aluno no AVA do curso (participação em chats, fóruns, listas de e-mails) (Vasconcelos et al, 2008; Moraes; Campos, 2006), além das provas escritas presencias de conclusão de disciplina, prevalentes segundo a legislação da Universidade Aberta do Brasil (UAB). Tal concepção aplica-se aos modelos da EaD semipresencial e da EaD virtual (Moran, 2009) e revelam diversas fragilidades, ao se distanciarem dos processos vividos pelos alunos ao navegarem no ciberespaço, onde interagem com conteúdos e usuários diversos e participam em processos de cognição distribuída, ampliando e aprofundando processos de aprendizagem.

No campo teórico da EaD, tem-se trabalhado com algumas esferas da avaliação do aluno. Campos et al (2003) identificam quatro esferas, a "Tradicional" (com utilização de verificações de curto prazo e prazo mais longo e uso de reforço negativo 
através de punições e de reforço positivo através de sistemas de classificação), a tecnicista (baseada em comportamentos observáveis e mensuráveis), a libertadora lavaliação da prática vivenciada entre educador/educando e da autoavaliação do aluno) e a progressista (realizada a qualquer momento do curso, para diagnosticar falhas, observar desempenho e valorizar instrumentos não formais de avaliação). Em consonância com a proposição crítica de Campos et al (2003), alguns autores (Santos, 2005; Caldeira, 2004) estabelecem outras instâncias, identificadas como:

a) Avaliação somativa: procura avaliar a capacidade do aluno em discorrer sobre os conteúdos curriculares da disciplina e em geral é aplicada em momentos predefinidos, no meio e no encerramento da disciplina;

b) Avaliação formativa: ocorre ao longo do processo de aprendizagem do aluno, quando o professor procura atuar identificando pontos fortes e fracos do aprendiz, auxiliando-o a superar suas dificuldades e a consolidar suas qualidades;

c) Avaliação mediadora: o professor atua como um mediador e estimula o diálogo com o aluno, valendo-se das tecnologias de comunicação, sobre as dificuldades de aprendizagem ao longo da disciplina, com vistas à sua superação;

d) Autoavaliação: o aluno é estimulado a desenvolver processos de metacognição, em que toma consciência do seu processo de aprendizagem, dos níveis de participação nas atividades propostas e de sua dedicação ao curso, com vistas a melhorar tais processos e obter ganhos significativos de aprendizagem.

As práticas de avaliação correntes em EaD, no entanto, têm recebido críticas de pesquisadores da área, como Silva e Silva (2008, p. 5), ao afirmarem que "observa-se que nesses ambientes, tal como no ensino presencial, essa avaliação é feita segundo uma abordagem tradicional, com ênfase em avaliações somativas, em sua grande maioria realizadas por meio de testes on-line" e de exames presenciais obrigatórios, segundo o Decreto $n^{0}$ 5.622, de 19 de dezembro de 2005 (MEC, 2005). Ao criticar e apontar o caráter contraditório da obrigatoriedade da avaliação presencial imposta aos cursos de EaD, Moran (2009, p. 66) articula outras possibilidades de avaliação presencial, citando "seminários, apresentação de resultados de projetos, discussões orais e muitas outras", sem, no entanto, tratar das formas de avaliação que atendam à especificidade e natureza de práticas de ensino e aprendizagem relacionadas ao paradigma da cibercultura e da Web 2.0.

Na perspectiva de Moran, Polak (2009) reconhece que a avaliação em EaD necessita de novo enfoque e propõe uma avaliação que posicione o aluno enquanto autor do processo de reconstrução do conhecimento, reconhecendo seu caráter 
processual. Ao enfatizar a importância da avaliação formativa durante o processo de EaD, a autora destaca modelos e ferramentas de avaliação on-line dos diversos ambientes colaborativos de aprendizagem disponíveis. Polak (2009, p. 155) afirma que "um processo de avaliação formativa se completa com outros elementos, como, por exemplo, portfólios, fóruns, listas de discussão, seminários virtuais, chats, etc. Os inúmeros modelos de sistemas colaborativos existentes e suas respectivas ferramentas de comunicação e interação visam à melhoria da avaliação em EAD."

Avançando em relação à Moran e Polak, Bassani e Behar (2009, p. 94) propõem que "a avaliação deve enfocar o caráter dinâmico e não-linear da aprendizagem". As autoras enfatizam a importância de realizar a avaliação do produto situando-o no processo de aprendizagem, evitando descontextualizá-lo, portanto, do processo vivenciado pelo aluno. A partir de tal perspectiva, as autoras identificam as possibilidades de avaliação do aluno no AVA, descrevendo e analisando esferas, modalidades e ferramentas e propondo que "a avaliação da aprendizagem no plano individual pode levar em conta aspectos quantitativos, evidenciados a partir do número de acessos (no AVA, na disciplina e na ferramenta) e/ou qualitativos, diretamente relacionados ao conteúdo das mensagens postadas" (Bassani e Behjar, 2009, p. 103).

Santos (2006) propõe a avaliação do processo de aprendizagem do aluno em que o professor deverá coletar (podendo contar com a ajuda de sistemas automatizados do AVAl e analisar nove tipos de informações e dados, entre eles os caminhos percorridos pelo aluno no material de estudo fornecido pelo professor, a frequência de consultas a fontes fornecidas pelo professor e aquelas localizadas pelos próprios alunos, ações e participação colaborativa do aluno, regularidade do contatos do aluno com o professor ao longo do período de estudos. São ações do docente que, em parte, procuram contemplar atividades intrínsecas às práticas do aluno da modalidade EaD, ainda que possam, em certa medida, estar presentes também na modalidade presencial.

A autora também se refere a ferramentas de mineração de dados baseadas, por exemplo, nas mensagens postadas pelos alunos em espaços como o fórum e os batepapos do AVA. Nesse caso, afirma Santos (2006, p. 263), as tarefas de mineração de dados poderiam ajudar o professor na avaliação relativa à classificação dos alunos segundo níveis de participação e sua contribuição nessas atividades. Poderiam, ainda, realizar regressão de dados, para estimar a quantidade de mensagens emitidas ao longo do curso, e associação de dados, permitindo identificar itens (tópicos do conteúdo programático, por exemplo) que mais interessam ao aluno, podendo mapear a ação dos alunos acerca desses tópicos (com o uso de palavraschaves, por exemplo). Otsuka e Rocha (2002) também apresentam uma detalhada revisão sobre a tecnologia de agentes automatizados empregadas em diversos AVA. Tais agentes fornecem informações importantes para auxiliar em alguns aspectos da 
avaliação do aluno ao realizar atividades e se comunicar pelo ambiente institucional de aprendizagem.

Há importantes avanços na proposição dos autores citados, em particular no que se refere à crítica da avaliação somativa baseada em testes formais, que procura mensurar a aprendizagem do aluno, sejam esses testes presenciais ou on-line. Destaca-se, também, a proposição, pelos autores, de que ferramentas disponibilizadas nos AVA, como fóruns, mensagens e portfólios, sejam utilizadas para avaliar as atividades dos alunos ao longo da disciplina, destacando-se frequência de acesso do aluno, interações com colegas e tutores em fóruns e chats. Tais possibilidades permitem a visualização, compreensão e consequente avaliação mais ampliada e dinâmica do processo de aprendizagem do alunos.

Porém, as fronteiras formais da ação do aluno - e, portanto, de sua avaliação continuam circunscritas ao AVA do curso, ou seja, ao espaço virtual articulado pela instituição de ensino e destinado às ações do curso ladicionadas às atividades de sala de aula para o caso dos cursos da modalidade semipresencial). A prática de algumas instituições e de alguns cursos, por sua vez, revela a tentativa de se constituir valor para a avaliação de algumas atividades dos alunos fora do AVA. É o caso do aluno que recebe um elogio do tutor ou uma pontuação mais elevada por ter compartilhado um artigo, encontrado na internet, com os colegas de turma no fórum da disciplina. No entanto, essas ocorrências não têm sido resultado de formulações teóricas articuladas aos princípios da cibercultura e da Web 2.0. Contemplam uma parcela ínfima das atividades dos alunos fora do AVA e não integram sistemas formais e institucionalizados de avaliação da grande maioria das instituições que atuam na modalidade da EaD.

Compreende-se a necessidade da formulação de parâmetros institucionais de avaliação para que se possa gerenciar grandes contingentes de alunos envolvidos em EaD, o que tem ensejado linhas de pesquisa sobre ferramentas que consigam captar interações, postagens e a presença virtual para que se possa avaliar ações e atividades dos alunos no AVA do curso. Porém, assim como a aprendizagem presencial extrapolou os muros da escola, a aprendizagem na modalidade da EaD não se limita às ações e atividades do aluno no AVA, demandando, dessa forma, novas perspectivas e práticas de avaliação.

\section{Cibercultura e Web 2.0}

Lemos (2003) identifica três "leis" da cibercultura: emissão, conexão e reconfiguração. Por emissão o autor indica a prática crescente do "faça você mesmo", muito clara, por exemplo, nos milhares de vídeos postados por brasileiros das 
diversas classes sociais em web sites hoje bastante populares, como o YouTube, e das extensas listas de comentários nas páginas em que os vídeos são disponibilizados. Tal ocorrência indica que o polo da emissão, tradicionalmente associado aos grandes veículos de comunicação de massa, democratizou-se, permitindo que muitos emitam para muitos. A segunda lei relaciona-se ao princípio de conexão. Não basta produzir conteúdos (vídeos, blogs, podcasts, chats, etc.), é preciso compartilhá-los através das conexões permitidas pelas redes. A liberação da emissão e a difusão em rede levam, segundo Lemos, à terceira lei da cibercultura, a reconfiguração de práticas sociais, instituições e modalidades midiáticas. Isso se traduz em novas modalidades de consumo de bens culturais, renovados formatos de produção de bens simbólicos, e em novas perspectivas sobre o sentido de propriedade e autoria, personalização e massificação. E nos leva a um nível maior de complexidade na interseção do usuário com o ciberespaço, onde ocorre a apropriação criativa que é

ao mesmo tempo, forma de utilização, aprendizagem e domínio técnico, mas também forma de desvio (deviance) em relação às instruções de uso, um espaço completado pelo usuário na lacuna não programada pelo produtor/inventor, ou mesmo pelas finalidades previstas inicialmente pelas instituições. (Lemos, 2004, p. 239).

A perspectiva da cibercultura nos traz a compreensão de que o aluno, ao inserir-se no ciberespaço para articular momentos de aprendizagem, conecta-se com diversas redes humanas e redes constituídas por materiais/conteúdos relacionados às disciplinas cursadas. Disso decorre uma produção e compartilhamento de conteúdos e saberes e outras formas de vivenciar tais experiências, aproximando-se da reconfiguração das práticas a que Lemos se refere na perspectiva dos fundamentos da cognição distribuída (Nardi, 1995). Constitui-se aí uma expansão, uma busca de sentido pelo aluno no contexto do estudo curricular, em geral com o objetivo pragmático de ampliar a compreensão sobre os conteúdos da disciplina e realizar as atividades programadas - tais experiências podem ter caráter negativo, como a simples cópia de conteúdos prontos, ou positivo, como a articulação e síntese de conteúdos próprios que revelam uma reflexão mais complexa por parte do aluno com os colegas de disciplina.

Há nessa expansão teórica e prática indicada pela cibercultura algumas dificuldades a serem enfrentadas e também oportunidades a serem exploradas no universo atual da EaD. As dificuldades dizem respeito particularmente ao perfil heterogêneo dos alunos de $\mathrm{EaD}$, com parcelas significativas de egressos das camadas da população menos favorecidas socioeconomicamente, o que resulta em menor acesso às TICs e, em muitos casos, em habilidades de letramento digital menos desenvolvidas lem particular quanto ao uso e à compreensão das ferramentas digitais) para fins de 
estudo e aprendizagem. Esse perfil parece ter ligação com o fato de que grande parte dos conteúdos disciplinares de EaD ainda seguem a lógica dos conteúdos impressos na tradição do livro, ainda que sejam disponibilizados ao aluno também em formato digital. Na UAB prevalece a sistemática de distribuição de apostilas aos alunos, constituindo a centralidade da disciplina cursada, tendo as atividades on-line como complementares, dentre elas a participação em fóruns de discussão e a postagem de trabalhos em formato digital no AVA do curso.

Além de se distanciarem dos paradigmas da cibercultura e da Web 2.0, esses elementos que hoje preponderam nas práticas de $\mathrm{EaD}$ no país podem estar, de fato, contribuindo para a consolidação de práticas de EaD que "deseduquem" os alunos em termos de habilidades e compreensões no campo do letramento digital que adquirem cada vez maior valor e importância no contexto da cibercultura e da Web 2.0, limitando possibilidades de aprendizagens significativas continuadas. Em estudo recente, sob a coordenação do autor, constatou-se que alunos de $\mathrm{EaD}$, quando apresentados a um artefato multimodal dinâmico (texto e imagens em movimento) na internet, tendem a realizar uma navegação linear, com ênfase nos conteúdos textuais, esquivando-se de uma ação mais exploratória e autoral e extraindo mínimo proveito das diversas informaç̃̃es disponibilizadas nos hiperlinks e nos conteúdos imagéticos lgráficos, fotografias, vídeos). Em contraste, alunos dos cursos presenciais demonstraram maior tendência a explorar tais conteúdos com fins de aprendizagem. 0 estudo revelou, portanto, uma cristalização de práticas mais tradicionais (navegação linear, ênfase aos conteúdos textuais) dos alunos de EaD participantes da pesquisa, justamente aqueles que poderiam estar obtendo melhor proveito dos diversos materiais disponibilizados na internet e de práticas colaborativas on-line para a sua aprendizagem.

Outra dificuldade refere-se à capacidade do aluno de EaD para localizar e acessar as informações disponibilizadas na internet, sejam textuais ou imagéticas, e de processar tais informações de modo crítico para ampliar, relativizar ou criticar conteúdos disciplinares. Estudo desenvolvido por pesquisadora da Universidade Estadual da Califórnia (Rosenblatt, 2010) corrobora crença de que tal prática ainda representa dificuldade substantiva para muitos alunos. 0 estudo revelou que metade dos alunos envolvidos se limitaram a resumir alguns conteúdos que encontraram na internet, não sendo capazes de sintetizar tais conteúdos e realizar conexões para ampliar os conteúdos trabalhados pelo professor da disciplina. Esses resultados indicam alguns limites de boas práticas de letramento digital e de localização de conteúdos válidos no ciberespaço se esses não se constituírem como oportunidade de reflexão crítica e síntese conceitual para o aluno. Constituem-se como elementos contraditórios presentes no fenômeno da cibercultura e da Web 2.0. que indicam a complexidade do fenômeno tratado sem, no entanto, invalidar a problemática e argumentação aqui desenvolvidas. 


\section{Novas perspectivas de avaliação do aluno}

Para práticas de EaD que propõem incorporar os paradigmas da Web 2.0 e da cibercultura, estabelece-se a necessidade de ênfase no letramento digital, uso de conteúdos hipermodais, adesão a atividades colaborativas e desenvolvimento da autonomia do aluno. Essa orientação teórica e prática permite efetivar formas de avaliação que valorizem tais experiências empreendidas pelo aluno da EaD no ciberespaço. Os eixos principais dessa perspectiva se articulam a partir de características do ciberespaço e sua linguagem e dos processos de cognição distribuída, bem como as proposições de Santaella (2004) sobre a navegação do ciberespaço.

A autora propõe que o leitor/navegador atual, tipificado como "leitor imersivo, virtual" (Santaella, 2004, p. 31), em geral agrega traços de diversos perfis, incluindo características do leitor:

a) contemplativo: associado às práticas de leitura linear, silenciosa, privada e solitária de livros, pinturas, gravuras e mapas;

b) movente: associado à fragmentação associada à comunicação midiática de massa e que em geral lê de forma apressada linguagens efêmeras, híbridas, misturadas;

c) imersivo: vive em estado de alerta e prontidão, conectando-se entre nós e nexos da rede, num roteiro hipermodal que coedifica ao interagir com os nós entre palavras, imagens e vídeos na rede.

A prática de navegação do leitor imersivo no ciberespaço agrupa características das três tipologias propostas por Santaella (2004, p. 180): as dos internautas errante, detetive e previdente. Ao navegar, portanto, o aluno adota a posição de explorador e cocriador. A autora argumenta que "o ideal é que esse leitor [ao navegar] não se entregue às rotinas sem imaginação do previdente, mas se abra para as surpresas, entregue-se às errâncias para poder voltar a vestir as roupas do detetive, farejando pistas".

Todas essas características posicionam o aluno da EaD como potencialmente um navegador imersivo, que desenvolve práticas de navegação do internauta errante, detetive e previdente, ainda que isso possa variar entre os alunos, entre os cursos e as disciplinas, dependendo de diversas especificidades cuja discussão ultrapassa o escopo deste artigo.

0 primeiro tópico das proposições de Santaella (2004) a ser detalhado referese à hibridização de linguagens, processos sígnicos, códigos e mídia. Apesar da preponderância de conteúdos verbais do ciberespaço, cresce a cada dia a presença 
e disponibilidade de conteúdos multimídia, em particular com a disponibilização de trechos de conteúdos midiáticos dos grandes grupos corporativos linclusive grandes editoras de livros) e da proliferação de vídeos domésticos, tendo sua face mais visível na riqueza temática e autoral reunida pelos sites YouTube ou Vimeo. Apenas o projeto de digitalização do Fundo Última Hora, sob guarda do Arquivo Público do Estado de São Paulo, prevê a publicação de 600 mil imagens do histórico jornal (Arquivoestado, 2011).

Apesar da fragilidade conceitual e da superficialidade de grande parte da produção multimídia em circulação no ciberespaço, é importante valorar usos de linguagens não verbais pelos alunos. Isso se aplica ao consumo dessas linguagens lum vídeo na temática da disciplina, uma imagem de caráter histórico ou técnico que agregue informação a um textol e à produção e disseminação desses conteúdos na internet - o aluno poderá produzir um vídeo a ser compartilhado na internet e poderá ler os comentários relacionados postados pelos internautas e responder a estes. Essas experiências do aluno ou de um grupo de alunos pode ser compartilhada com os demais cursistas e deve ser valorizada pelo professor. 0 aluno poderá refletir sobre o processo de produção, as interações com os demais internautas e os avanços e questionamentos em relação aos conteúdos tratados na disciplina.

0 segundo tópico refere-se à capacidade de armazenar informações e transmutálas em diversas versões, quando o receptor torna-se coautor. Ao navegar pelo ciberespaço em busca de conteúdos das disciplinas cursadas, o aluno cria a oportunidade de participar em redes virtuais de aprendizagem, que podem constituirse entre pessoas com diferentes níveis de saber entre o aluno com os diversos materiais disponibilizados na internet, e entre os alunos, os materiais e outros alunos com quem possa estabelecer relações colaborativas.

Nesses casos, conteúdos, contatos, perspectivas inesperadas podem ter impacto positivo na aprendizagem do aluno, pois ele pode colaborar com outros com interesses similares, mas que possuam diferentes perspectivas quanto aos conteúdos em estudo. Dessa colaboração têm surgido diversos novos materiais, que incluem breves comentários em um fórum de discussão de uma comunidade ou produções colaborativas diversas, como textos de multiautoria linclusive através da tecnologia Wikil, vídeos e outros conteúdos multimídia em que diversos autores contribuem com ideias e capacidades que se agregam ao longo do processo produtivo e resultam em produtos finais únicos.

Nesse aspecto, caberá ao professor valorizar produtos e conteúdos “originais”, produzidos pelos alunos e disponibilizados na internet. Os alunos podem relatar sobre a utilização, para fins de estudo e aprendizagem, de serviços e web sites (como 4shared, Scribd), blogs e redes sociais. Também podem indicar como, quando e onde se engajaram em diálogos e trocas com outros e como tais interações interferiram, 
de forma positiva ou não, para a aprendizagem ao longo da disciplina cursada.

0 terceiro tópico refere-se ao cartograma navegacional, incluindo os recursos de busca e filtragem, ou seja, o mapeamento e a valorização das práticas de navegação hipermodal do aluno. Tal prática reflete as formulações de Manovich (2001), que conceitua a internet como uma extensa base de dados desordenada, em que caberá ao aluno construir seus próprios percursos a fim de atingir objetivos associados ao processo de aprendizagem em que está envolvido. Nesse sentido, o aluno de EaD estará aprendendo a navegar, a localizar e a selecionar conteúdos válidos para tais fins de aprendizagem. Hoje esse processo é praticamente invisível. Ao se realizar a avaliação desse aluno, todo esse trabalho não constitui valor formal de aprendizagem, pois o aluno não recebe uma nota ou conceito por esses esforços. Será preciso mudare valorizar essas atividades, que podem consumir horas de estudo desses alunos. Cabe também valorizar a utilização de programas e aplicativos que maximizem as práticas de estudo, como organizadores de bibliotecas, uso de tags para armazenamento e busca dos arquivos selecionados, entre outros.

O professor poderá criar instrumentos de avaliação bastante úteis: poderá pedir ao aluno para registrar a navegação que realiza em tela, utilizando programas de gravação (também conhecidos como programas de captura de vídeo, entre eles o Camtasia Studio e o Hypercam) ou mapeadores da navegação (como o Nestor Cartographer) e posterior envio ou disponibilização desses arquivos para avaliação; o professor poderá pedir ao aluno que reflita sobre essas trajetórias de navegação, permitindo que desenvolva uma metacognição sobre a forma como conduz suas pesquisas na internet para fins de estudo; e o professor poderá solicitar que o aluno apresente um mapa de interações virtuais nos momentos de estudos, incluindo as postagens e interações em fóruns e comunidades virtuais na temática dos conteúdos das disciplinas. Por fim, o aluno poderá apresentar trabalhos sobre os conteúdos acessados, privilegiando-se nesse caso não a mera sumarização, mas a síntese crítica, para questionar e/ou aprofundar elementos dos conteúdos trabalhados na disciplina.

Os diversos aspectos da navegação do aluno no ciberespaço articulados por Santaella (2004), aliados às características da cibercultura e à natureza midiática e comunicacional da Web 2.0, indicam a necessidade de uma perspectiva renovada quanto à avaliação do aluno, em particular para aqueles da modalidade EaD. Essa nova perspectiva abrange todas as ações do aluno no ciberespaço e podem ser traçadas através do uso das diversas ferramentas que registram a navegação do estudante, o acesso e uso dos materiais diversos e as trocas comunicativas que ocorrem no contexto da aprendizagem. A partir desses registros, pode-se atribuir valor a tais ações, ampliando o conjunto de metodologias e instrumentos utilizados pelo professor para avaliar a aprendizagem dos alunos na contemporaneidade. 


\section{Considerações finais}

A articulação e implementação de novas formas de avaliação em EaD, dado o perfil dos alunos de $\mathrm{EaD}$ e o estado das práticas correntes da modalidade hoje no país, constituem desafios a serem superados. Ultrapassadas as limitações de acesso e uso das TICs, de baixo letramento digital de setores da sociedade, e de compreensão das possibilidades de ensino e aprendizagem oferecidas pelo ciberespaço, tratar-se-ão de valorizar as ações produtivas dos alunos no ciberespaço.

Para isso será necessário discutir e atualizar concepções, práticas e ferramentas que hoje preponderam na modalidade $\mathrm{EaD}$. 0 objetivo deverá ser uma aproximação produtiva entre as potencialidades da Web 2.0, as iniciativas dos alunos ao navegarem na Internet e as possibilidades de aprimoramento dos processos de aprendizagem. Isso não deverá ocorrer em detrimento da riqueza e importância das atividades presenciais, do uso dos materiais impressos, em particular os livros, e da mediação do professor/tutor. Deverá nortear-se por princípios bem delineados, visto que

a aplicação eficaz das tecnologias digitais consiste em enriquecer o mundo do aprendiz para sustentar interações produtivas e favorecer o desenvolvimento de sua inteligência. Não são os métodos e as técnicas de ensino, como se acreditou, que vão melhorar as aprendizagens, muito pelo contrário, são as atividades de trocas, as atividades exploratórias, experimentais, as atividades de comunicação, as atividades interativas, de colaboração e de cooperação entre os aprendizes e as pessoas (colegas e professores), entre os aprendizes e as fontes de informações que favorecerão as aprendizagens. (Fagundes, 2008, p. 10).

As proposições apresentadas possuem implicações também para a gestão da avaliação, pois aprofundam as dificuldades já apontadas por Polak (2009) ao referirse ao acompanhamento dos aspectos considerados mais informais, dificuldade oriunda do que a autora considera como limitações das ferramentas existentes, reconhecendo sua potencial superação pela crescente evolução tecnológica. Há implicações também para a formação de professores e tutores de EaD cujas especificidades escapam ao objetivo deste trabalho. Cabe ressaltar, porém, que o papel de mediador torna-se ainda mais fundamental, contrapondo-se à perspectiva do professor como transmissor de conteúdos. Estabelece-se a ênfase em formação que privilegie a perspectiva construtivista associada à sociointeracionista, que, no entanto, não pode dissociar-se das especificidades trazidas pela cibercultura e pela Web 2.0, essas cada vez mais integradas à vida de muitos alunos, em particular no que se constitui, hoje, a experiência de aprender em rede. 
Ao se propor articular e valorizar práticas de estudo no ciberespaço, será importante considerar também o fato de que a incorporação de ferramentas tecnológicas aos processos de aprendizagem transforma a atividade cognitiva do aluno. Isso pode ocorrer quando ferramentas muito eficientes dominam o processo cognitivo, criando menos oportunidade para que o aprendiz se engaje em processos reflexivos (Karasavvidis, 2002). Será necessário, portanto, articular pontos de equilíbrio nessas práticas que priorizem o avanço da atividade cognitiva e da aprendizagem dos alunos no ciberespaço, aliadas às novas perspectivas de avaliação.

\section{Referências}

ARQUIVOESTADO. Fotografias. Negativos da UH. Disponível em: <http://www. arquivoestado.sp.gov.br/uhdigital/imagens.php>. Acesso em: 10 jan. 2011.

BASSANI, Patrícia e BEHAR, Patrícia. Avaliação da aprendizagem em ambientes virtuais. In: BEHAR, Patrícia e colaboradores. Modelos pedagógicos em educação a distância. Porto Alegre: ARTMED, 2009.

CALDEIRA, Ana Cristina. Avaliação da Aprendizagem em Meios Digitais: Novos Contextos, 2004. Disponível em: <http://www.abed.org.br/congresso2004/por/htm/033-TCA4.htm>. Acesso em: 10 mai. 2011.

. A avaliação da aprendizagem na educação online: uma experiência do MiniWeb Cursos. In: SILVA, Marcos e SANTOS, Edméa. Avaliação da aprendizagem em educação online. São Paulo: Edições Loyola, 2006.

CAMPOS, Fernanda et al. Cooperação e aprendizagem on-line. Rio de Janeiro: DP\&A, 2003.

FAGUNDES, Léa. Tecnologia e educação: a diferença entre inovar e sofisticar as práticas tradicionais. Revista Fonte, Dez. 2008.

KARASAVVIDIS, Ilias. Distributed cognition and educational practice. Journal of Interactive Learning Design, v. 13, p. 11-29, 2002.

LEMOS, André. Cibercultura. Alguns pontos para compreender nossa época. In: LEMOS, André e CUNHA, Paulo (Orgs). Olhares sobre a Cibercultura. Porto Alegre: Sulina. 2003.

MANOVICH, Lév. The language of new media. Cambridge, MA: The MIT Press, 2001.

MEC (Ministério da Educação). Decreto no 5622, 2005. Disponível em:<http://portal.mec. gov.br/seed/arquivos/pdf/dec_5622.pdf>. Acesso: 2 dez. 2010.

MORAES, Raquel e CAMPOS, Gustavo. Avaliando futuros educadores em OEB online no CEADUnB Virtual: uma perspectiva emancipatória e humanista. In: SILVA, Marcos e SANTOS, Edméa. Avaliação da aprendizagem em educação online. São Paulo: Edições Loyola, 2006.

MORAN, Manuel. EaD - Por que não? Educação Temática Digital, Campinas, v.10, n.2, p.5470, jun. 2009. 
NARDI, Boni. Context and consciousness: activity theory and human-computer interaction. Cambridge, MA: The MIT Press, 1995.

OTSUKA, Joice e ROCHA, Heloísa. Avaliação formativa em ambientes de EaD. Anais do XIII Simpósio Brasileiro de Informática na Educação, SBIE, UNISINOS, 2002.

SANTAELLA, Lúcia. Navegar no ciberespaço: o perfil cognitivo do leitor imersivo. São Paulo: Paulus, 2004.

PEA, Roy. Practices of distributed intelligences and designs for education. In: SALOMON, Gavriel (ed.). Distributed cognitions: Psychological and educational considerations. New York: Cambridge University Press, 1993.

POLAK, Ymiracy. A avaliação do aprendiz em EaD. In: LITTO, Fredric e FORMIGA, Marcos (Orgs.). Educação a distância. 0 estado da arte. São Paulo: Pearson, 2009.

SANTOS, João. Avaliação no ensino a distância. Revista Ibero-americana de Educação. Número 38/4. Disponível em: <http://www.rieoei.org/1372.htm>. Acesso em: 10 maio 2011.

SANTOS, Neide. Desafios da web: como avaliar os alunos online. In: SILVA, Marcos e SANTOS, Edméa. Avaliação da aprendizagem em educação online. São Paulo: Edições Loyola, 2006.

SILVA, Angela; SILVA, Christina. Avaliação da aprendizagem em ambientes virtuais: rompendo as barreiras da legislação. In: Congresso Internacional de Educação a Distância. Santos: ABED, 2008. Disponível em: <www.abed.org.br/congresso2008/ tc/510200863228PM.pdf >. Acesso: 7 jan. 2011.

VASCONCELOS, Francisco et al. Avaliação Sócio-Interacionista Aplicada ao Contexto da EaD em Cursos de Graduação Semi-Presenciais Mediado por um Ambiente Virtual de Aprendizagem In: XXVIII Congresso da Sociedade Brasileira de Computação no XVI WIE Workshop Sobre Informática na Escola, 2008, Belém. Anais do SBC. Belém : SBC, 2008.

Recebido em março de 2012

Aprovado em maio de 2012

Eduardo Santos Junqueira, Ph.D. em Educação pela Michigan State University. Professor Adjunto na Universidade Federal do Ceará - UFC, vinculado ao Instituto Universidade Virtual e ao Programa de Pós-Graduação em Educação Brasileira. É líder do grupo de pesquisa Linguagens e Educação em Rede (LER) e coordena projeto de pesquisa sobre a navegação hipermodal de alunos da modalidade educação a distância. Publicações recentes: Conteúdos hipermodais para fins de aprendizagem: usos em contexto pelos alunos (2010); Epistemologias digitais e comunidades de prática: problematizando a inclusão digital difusionista e tecnicista (2011). E-mail: eduardojavirtu 